\title{
Alkaloid and other Chemical Constituents from Psychotria stachyoides Benth.
}

\author{
Antonia T. A. Pimenta, ${ }^{a}$ Daniel E. A. Uchôa, ${ }^{a}$ Raimundo Braz-Filho, ${ }^{\#, b}$ \\ Edilberto R. Silveira ${ }^{a}$ and Mary Anne S. Lima*,a \\ ${ }^{a}$ Departamento de Química Orgânica e Inorgânica, Universidade Federal do Ceará, \\ CP 12200, 60021-940 Fortaleza-CE, Brazil \\ ${ }^{b}$ Centro de Ciências, Universidade Estadual do Norte Fluminense and \\ Universidade Federal Rural do Rio de Janeiro, Campos dos Goytacazes-RJ, Brasil
}

\begin{abstract}
Os extratos orgânicos das folhas e raízes de Psychotria stachyoides forneceram o novo alcaloide indólico monoterpênico glicosilado N-desmetil-correantosida, além de bizantionosida B, $\alpha$-amirina, éter metílico da alizarina, rubiadina, escopoletina, ácido barbinévico e uma mistura de $\beta$-sitosterol e estigmasterol glicosilados. A caracterização estrutural dos compostos isolados foi estabelecida com base na espectroscopia no infravermelho (IR), espectrometria de massa (MS) e particularmente ressonância magnética nuclear (RMN) 1D e 2D.
\end{abstract}

\begin{abstract}
The organic extracts of leaves and roots of Psychotria stachyoides provided the new glucoside monoterpenoid indole alkaloid $\mathrm{N}$-demethylcorreantoside, besides bizantionoside $\mathrm{B}, \alpha$-amyrin, alizarine methyl-ether, rubiadine, scopoletin, barbinevic acid and a mixture of $\beta$-sitosterol and stigmasterol glucosides. The structural characterization of the isolates was established based on infrared spectroscopy (IR), mass spectrometry (MS) and, particularly, 1D and 2D nuclear magnetic resonance (NMR).
\end{abstract}

Keywords: monoterpene indole alkaloid, coumarins, naphthoquinones, triterpenes, Psychotria stachyoides

\section{Introduction}

Indole alkaloids represent the biggest single class of all alkaloids from plants. The major groups under investigation are the ones with monoterpene $\left(\mathrm{C}_{10}\right)$ or nor-monoterpene $\left(\mathrm{C}_{9}\right)$ moieties joined to the tryptamine, which are distributed on a wide range of different structures in the Apocynaceae, Loganiaceae, Nyssaceae and Rubiaceae families. The genus Psychotria (Rubiaceae) comprises more than 1000 species distributed in tropical regions worldwide. This genus is taxonomically complex, and is particularly characterized as a prolific source of bioactive polyindole and monoterpenoid indole alkaloids. Previous phytochemical studies of species of Psychotria from the Southern Brazil have revealed the remarkable presence of glycosylated indole monoterpenoid alkaloids. ${ }^{1}$

As part of the investigative efforts to find alkaloids from Rubiaceae species of the Northeastern Brazil flora, Psychotria

*e-mail: mary@dqoi.ufc.br

\#Emeritus Professor from FAPERJ/UENF/UFRRJ stachyoides (subgroup Heteropsychotria), a shrub growing predominantly in tropical and sub-tropical forests from Brazil (where it is popularly named as "erva-d'anta"), ${ }^{2}$ has been investigated. This work reports the isolation and structural characterization of the new glucosilated monoterpene indole alkaloid named as $\mathrm{N}$-demethylcorreantoside (1) from the leaves of $P$. stachyoides, in addition to the known bizantionoside B and $\alpha$-amyrin. ${ }^{3,4}$ Chemical investigation of the roots yielded alizarin methyl-ether, ${ }^{5}$ rubiadine, ${ }^{6}$ scopoletin, ${ }^{7}$ barbinevic acid ${ }^{8}$ and a mixture of $\beta$-sitosterol and stigmasterol glucosides. ${ }^{9}$

\section{Results and Discussion}

The molecular formula of compound $\mathbf{1}$ was established by the positive mode HRESIMS (electrospray ionization mass spectrometry) peak at $\mathrm{m} / \mathrm{z}, 499.2039\left([\mathrm{M}+\mathrm{H}]^{+}\right.$ $\left(497.9654+1.00783\right.$ calcd. for $\left.\mathrm{C}_{26} \mathrm{H}_{30} \mathrm{~N}_{2} \mathrm{O}_{8}+\mathrm{H}\right)$. The IR spectrum implied the presence of hydroxyl $\left(3414 \mathrm{~cm}^{-1}\right)$ and lactam $\left(1675 \mathrm{~cm}^{-1}\right)$ functionalities. From the ${ }^{1} \mathrm{H}$ NMR spectrum, a tetrahydro- $\beta$-carboline system was defined by 
the typical aromatic signals at $\delta 7.22(\operatorname{td}, J 7.4$ and $1.0 \mathrm{~Hz}$, H-10), 7.26 (td, $J 7.4$ and $1.3 \mathrm{~Hz}, \mathrm{H}-11$ ), 7.45 (dd, $J 7.4$ and $1.3 \mathrm{~Hz}, \mathrm{H}-9$ ), 8.15 (dd, $J 7.4$ and $1.0 \mathrm{~Hz}, \mathrm{H}-12$ ), besides the two methylenes at $\delta 3.10(\mathrm{t}, J 5.5 \mathrm{~Hz}, 2 \mathrm{H}-5)$ and 2.70 (t, $J 5.4 \mathrm{~Hz}, 2 \mathrm{H}-6){ }^{10}$ The ${ }^{1} \mathrm{H}$ NMR spectrum also showed signals relative to an iridoid unit related to a secologanin moiety due to the signals of the olefinic hydrogen at $\delta 5.85$ (ddd, $J 17.6,10.0$ and $7.6 \mathrm{~Hz}, \mathrm{H}-19$ ), the vinylidene group at $\delta 5.20(\mathrm{~d}, J 10.0 \mathrm{~Hz}, \mathrm{H}-18 \mathrm{a})$ and $5.23(\mathrm{~d}, J 17.6 \mathrm{~Hz}, \mathrm{H}-18 \mathrm{~b})$, and the methines at $\delta 2.64(\mathrm{~m}, \mathrm{H}-20$ and $\mathrm{H}-15)$ and 5.74 (d, $J 8.7 \mathrm{~Hz}, \mathrm{H}-21) .{ }^{11}$ The sugar moiety was assigned as an O- $\beta$-D-glucopyranose on the basis of the larger $J$ value for the anomeric proton at $\delta 4.82\left(\mathrm{~d}, J 8.2 \mathrm{~Hz}, \mathrm{H}-1^{\prime}\right)$.

The presence of the monoterpenoid unit was confirmed by analysis of the ${ }^{1} \mathrm{H},{ }^{1} \mathrm{H}$ COSY NMR data. This spectrum exhibited correlations for the hydrogens at $\delta 5.74(\mathrm{H}-21)$ and 2.64 (H-20), which in turn, showed correlation to the hydrogen at $\delta 5.85(\mathrm{H}-19)$. The strong correlations observed for the methine hydrogen at $\delta 4.20(\mathrm{H}-3)$ and the methylene group at $\delta 1.98(\mathrm{H}-14 \alpha)$ and $2.10(\mathrm{H}-14 \beta)$ suggested that the secologanin unit was attached to the $\mathrm{C}-3$ carbon, as reported for other similar monoterpenoid alkaloids. ${ }^{10}$ This suggestion was supported by the ${ }^{13} \mathrm{C}$ NMR spectrum along with the distortionless enhancement by polarization transfer (DEPT 135), that revealed 26 carbons atoms corresponding to three methylenes, one oxymethylene and one vinylidene, three methines, two hemiketal methynes and four oxymethines, six monohydrogenated $\mathrm{sp}^{2}$ carbons, and six non-hydrogenated carbons. However, the confirmation of the structure of $\mathbf{1}$ was supported by the HMQC and HMBC (heteronuclear multiple quantum coherence and heteronuclear multiple bond coherence, respectively) experiments, that revealed the unequivocal assignments of its NMR data. Further evidences of a tetrahydro- $\beta$-carboline skeleton were possible by the observed long-range correlations in the HMBC spectrum, that showed the proton at $\delta 3.10(2 \mathrm{H}-5)$ correlated to the carbons at $\delta 50.6(\mathrm{C}-3)$ and $117.0(\mathrm{C}-7)$, while the proton at $\delta 2.70(2 \mathrm{H}-6)$ showed correlations to the carbon at $\delta 117.0(\mathrm{C}-7)$ and 136.0 (C-2). In particular, the linkage of the methylene carbon C-14 with C-3 was established by the key correlations of the methylene hydrogens at $\delta 1.98$ and $2.10(2 \mathrm{H}-14)$ with the carbons at $\delta 136.0(\mathrm{C}-2)$ and $50.6(\mathrm{C}-3)$. The glucosyl moiety positioned at $\mathrm{C}-21$, was supported by the correlation between the anomeric hydrogen at $\delta 4.82\left(\mathrm{H}-1^{\prime}\right)$ and the carbon at $\delta 97.5$ (C-21). The structure of 1 was finally elucidated by comparing the value of the deshielded signal relative to $\mathrm{H}-12(\delta 8.15)$, to those reported for typical monoterpenoid indole alkaloids $(\delta c a .7 .6) \cdot{ }^{12}$ This chemical shift difference to a more deshielded position provided the clue for the determination of a seven member lactam ring derived from the intramolecular condensation of the indole nitrogen $(\mathrm{N}-1)$ with the original carbonyl of the methyl ester of secologanin. Comparison of these spectral features with those related to correantoside, a monoterpene indole alkaloid previously isolated from $P$. correae, showed high similarity, ${ }^{12}$ with exception of the $\mathrm{N}$-methyl group at $\mathrm{N}-1$, present in correantoside but missing in $\mathbf{1}$.

The relative stereochemistry of $\mathbf{1}$ was established by the nuclear Overhauser spectroscopy (NOESY) experiment. In particular by the diagnostic nuclear Overhauser effect (nOe) cross-peaks observed for the hydrogen at $\delta 1.98$ (H-14 $\alpha)$ with the hydrogens at $\delta 2.64(\mathrm{H}-20)$, and for the hydrogen at $\delta 2.10(\mathrm{H}-14 \beta)$ with the hydrogen at $\delta 5.74$ $(\mathrm{H}-21)$, in agreement with the relative stereochemistry of correantoside. $^{12}$

From the above evidences, compound $\mathbf{1}$ was identified and named as the new N-demethylcorreantoside. The chemical structure and the observed key nOe correlations for compound $\mathbf{1}$ are presented in Figure 1.

(a)

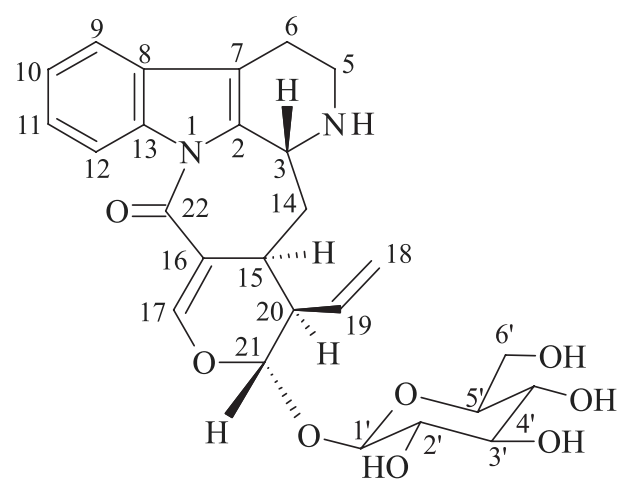

(b)

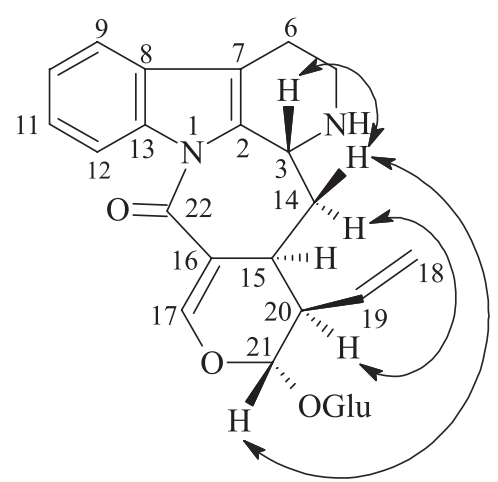

Figure 1. (a) Chemical structure and (b) observed key nOe correlations for compound 1 .

\section{Experimental}

\section{General experimental procedures}

Infrared (IR) spectra were recorded on a Perkin-Elmer FT-IR 1000 spectrometer (Waltham, USA) using $\mathrm{KBr}$ 
pellets. The NMR spectra were performed on a Bruker Avance DRX 500 spectrometer, equipped with an inverse detection probehead and z-gradient accessory working at $500.13\left({ }^{1} \mathrm{H}\right)$ and at $125.77 \mathrm{MHz}\left({ }^{13} \mathrm{C}\right)$, respectively. All pulse sequences are standard in the Bruker XWIN-NMR software, and all experiments were conducted at room temperature. The samples were dissolved in $\mathrm{CD}_{3} \mathrm{OD}(0.6 \mathrm{~mL})$ and transferred to $5 \mathrm{~mm}$ tubes. The ${ }^{1} \mathrm{H}$ and ${ }^{13} \mathrm{C}$ chemical shifts are expressed in the $\delta$ scale and were referenced to residual $\mathrm{CH}_{3} \mathrm{OH}$ at $\delta 3.31$ for proton and at $\delta 49.1$ for carbon. High resolution mass spectra (HRMS) were recorded on an UltrOTOF-Q mass spectrometer (LC-IP-TOF model 225-07100-34-SHIMADZU) either by positive or negative ionization modes of the ESI source. High-performance liquid chromatography (HPLC) analyses were performed on a Shimadzu chromatographer (Japan) equipped with a ternary pump (Shimadzu LC-20AT) and UV detector (Shimadzu SPD-M20A), using Phenomenex RP-18 columns (analytical: $250 \times 4.6 \mathrm{~mm}, 5 \mu \mathrm{m}$; semi-preparative: $250 \times 10 \mathrm{~mm}$, $10 \mu \mathrm{m})$. HPLC grade acetonitrile was purchased from Tedia Co. (São Paulo State, Brazil) and the HPLC grade water was obtained by a Milli-Q purification system (Millipore, Bedford, USA). Column chromatography was performed either over silica gel 60 (EMD, 70-230 mesh) or Sephadex LH-20 (Amersham Pharmacia Biotech, Uppsala, Sweden). Thin layer chromatography (TLC) was performed on precoated silica gel aluminum sheets (Merck) and the compounds were visualized by UV detection and by spraying with Dragendorff reagent or vanillin/perchloric acid/EtOH solution, followed by heating.

\section{Plant material}

Leaves and roots of Psychotria stachyoides Benth. were collected at the Pacoti County (Ceará State, Northeast of Brazil). Voucher specimens (\# 31674) were deposited at the Herbário Prisco Bezerra (EAC) and identified by Dr. Piero Giuseppe Delpret from the Institut de Recherche pour le Développement-IRD, UMR AMAP, Montpellier, France.

\section{Extraction and isolation}

Dried leaves of $P$. stachyoides $(2.7 \mathrm{~kg})$ were exhaustively extracted with $\mathrm{EtOH}(3 \times 9.0 \mathrm{~L})$ at room temperature. Evaporation of the solvent under vacuum yielded the ethanol extract $(130.0 \mathrm{~g})$. The ethanol extract was treated with $10 \%$ aqueous $\mathrm{HCl}$ and the acid solution was extracted with $\mathrm{CHCl}_{3}(3 \times 150 \mathrm{~mL})$. The aqueous phase was basified with $\mathrm{NH}_{4} \mathrm{OH}$ to $\mathrm{pH} 9-10$ and extracted with EtOAc $(3 \times 150 \mathrm{~mL})$. The organic fractions were combined and the solvent was evaporated to yield the alkaloid fraction $(2.2 \mathrm{~g})$. The alkaloid fraction (2.2 g) was chromatographed on Sephadex LH-20 by elution with $\mathrm{MeOH}$ to afford fourty two fractions $(20 \mathrm{~mL})$, that were combined into five resulting fractions after TLC analysis. Flash chromatography of fraction (2) ( $0.43 \mathrm{~g}$ ) using $\mathrm{CH}_{2} \mathrm{Cl}_{2} / \mathrm{MeOH} / \mathrm{NH}_{4} \mathrm{OH}$ (95:4:1) as eluent with increasing polarity yielded thirty one fractions $(20 \mathrm{~mL})$, which were pooled together in to four resulting sub-fractions according to TLC analysis. The sub-fraction (2)(4) (47.4 mg) was submitted to semi-preparative HPLC with a $\mathrm{C}_{18}$ column and using $\mathrm{CH}_{3} \mathrm{CN}-\mathrm{H}_{2} \mathrm{O}$ (7:3) TFA $0.2 \%$ system as eluent, to obtain $1(4.9 \mathrm{mg})$ and bizantionoside B $(6.3 \mathrm{mg})$. Successive flash chromatography from the non-alkaloidal fraction (3.0 g) by elution with hexane/EtOAc ( $9: 1$ ) yielded $\alpha$-amyrin (37.0 mg).

The EtOH extract of the roots $(50.4 \mathrm{~g})$ was redissolved in a mixture of $\mathrm{MeOH}: \mathrm{H}_{2} \mathrm{O}(1: 1 \mathrm{v} / \mathrm{v})$ and submitted to liquidliquid partition with hexane, $\mathrm{CH}_{2} \mathrm{Cl}_{2}, \mathrm{EtOAc}$ and n-BuOH to give the correspondent four fractions. The hexane fraction ( $3.9 \mathrm{~g})$ was re-chromatographed on Si gel by elution with hexane/EtOAc mixtures with increasing polarity to afford eighteen sub-fractions $(20 \mathrm{~mL})$, these fractions were combined into eleven sub-fractions according to TLC analysis. Chromatography of fraction (5) $(210.0 \mathrm{mg})$ by elution with hexane/EtOAc (3:1) yielded rubiadine (4.2 mg) and alizarin methyl ether $(7.1 \mathrm{mg})$, respectively. The $\mathrm{CH}_{2} \mathrm{Cl}_{2}$ fraction (2.6 g) was re-chromatographed on Si gel by elution with $\mathrm{CH}_{2} \mathrm{Cl}_{2} / \mathrm{MeOH}$ mixtures with increasing polarity, to give ninety two sub-fractions $(20 \mathrm{~mL})$, which were combined in nine resulting fractions according to TLC analysis. Fraction (2) yielded scopoletin (11.0 mg) and (4) yielded a mixture of $\beta$-sitosterol and stigmasterol glucosides (12.4 mg). Fraction (9) was re-chromatographed on Si gel by elution with hexane/EtOAc mixture with increasing polarity to yield barbinevic acid $(20.8 \mathrm{mg})$.

\section{N-Demethylcorreantoside (1)}

Brown solid, mp 200.6-202. $8^{\circ} \mathrm{C} ;[\alpha]_{\mathrm{D}}^{20}-173^{\circ}(c 0.075$, $\mathrm{MeOH})$; IR (KBr) $v_{\text {max }} / \mathrm{cm}^{-1}: 3414(\mathrm{O}-\mathrm{H}), 1675(\mathrm{C}=\mathrm{O})$, 1454, 1376, 1201,1166; ${ }^{1} \mathrm{H}$ NMR (500 MHz, CD 3 OD): 4.20 (dd, $J 7.3$ and $3.3 \mathrm{~Hz}, \mathrm{H}-3$ ), 3.10 (t, J 5.5 Hz, H-5), 2.70 (t, $J 5.5 \mathrm{~Hz}, \mathrm{H}-6), 7.45$ (dd, J 7.4 and 1,3 Hz, H-9), 7.22 (td, $J 7.4$ and $1.0 \mathrm{~Hz}, \mathrm{H}-10), 7.26$ (td, J 7.4 and $1.3 \mathrm{~Hz}, \mathrm{H}-11$ ), 8.15 (dd, J 7.4 and 1.0 Hz, H-12), 1.98 (m, H-14ß), 2.10 (m,

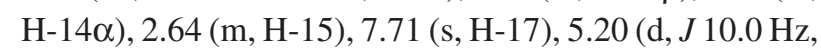
H-18b), 5.23 (d, J 17.6 Hz, H-18a), 5.85 (ddd, $J$ 17.6, 10.0 and 7.6 Hz, H-19), 2.64 (m, H-20), 5.74 (d, J 8.7 Hz, H-21), 4.82 (d, $\left.J 8.2 \mathrm{~Hz}, \mathrm{H}-1^{\prime}\right), 3.23$ (dd, $J 9.1$ and $8.2 \mathrm{~Hz}, \mathrm{H}-2^{\prime}$ ), 3.41 (t, $J 9.1 \mathrm{~Hz}, \mathrm{H}-3$ '), 3,.30 (t, $J 9.1 \mathrm{~Hz}, \mathrm{H}-4$ '), 3.32 (m, H-5'), 3.70 (dd, $J 11.9$ and $6.2 \mathrm{~Hz}, \mathrm{H}-6$ '), 3.93 (dd, $J 11.9$ and $1.9 \mathrm{~Hz}, \mathrm{H}-6$ ) ; ${ }^{13} \mathrm{C}$ NMR (125 MHz, CD $3 \mathrm{OD}$ ): 136.0 
(C-2), $50.6(\mathrm{C}-3), 40.0$ (C-5), 23.2 (C-6), 117.0 (C-7), 131.0 (C-8), 119.2 (C-9), 124.4 (C-10), 125.5 (C-11), 116.4 (C12), 137.3 (C-13), 36.7 (C-14), 35.7 (C-15), 112.7 (C-16), 155.6 (C-17), 119.3 (C-18), 135.2 (C-19), 45.6 (C-20), 97.5 (C-21), 168.6 (C-22), 100.7 (C-1'), 74.9 (C-2'), 78.7 (C-3'), 71.8 (C-4'), 78.2 (C-5'), 63.1 (C-6'); HRESIMS positive ions at $\mathrm{m} / \mathrm{z} 499.2039[\mathrm{M}+\mathrm{H}]^{+}$(calcd. for $\mathrm{C}_{26} \mathrm{H}_{30} \mathrm{~N}_{2} \mathrm{O}_{8}: \mathrm{m} / \mathrm{z}$ 497.9654).

\section{Supplementary Information}

Supplementary data associated with this paper are available free of charge at http://jbcs.sbq.org.br as PDF file.

\section{Acknowledgements}

The authors are grateful to Conselho Nacional de Desenvolvimento Científico e Tecnológico (CNPq), Coordenação de Aperfeiçoamento de Pessoal de Nível Superior (CAPES), Programa de Apoio a Núcleos de Excelência (PRONEX) e Fundação Cearense de Apoio ao Desenvolvimento Científico e Tecnológico (FUNCAP) for fellowships and financial support.

\section{References}

1. Both, F. L.; Kerber, V. A.; Henriques, A. T.; Elisabetsky, E.; Pharm. Biol. 2002, 40, 33; Kerber, V. A.; Passos, C. S.; Verli, H.; Fett-Neto, A. G.; Quirion, J. P.; Henriques, A. T.; J. Nat. Prod. 2008, 71, 697; Simões-Pires, C. A.; Farias, F. M.; Marston, A.; Queiroz, E. F.; Chaves, C. G.; Henriques, A. T.; Hostettman,
K.; Nat. Prod. Commun. 2006, 1101; Kerber, V. A.; Gregianni, T. S.; Paranhas, J. T.; Schwambach, J.; Farias, F.; Fett, J. P.; Fett-Neto, A. G.; Zuanazzi, J. A. S.; Quirion, J. C.; Elizabetsky, E.; Henriques, A. T.; J. Nat. Prod. 2001, 64, 677; Santos, L. V.; Fett-Neto, A. G.; Kerber, V. A.; Elizabetsky, E.; Quirion, J. C.; Henriques, A. T.; Biochem. Syst. Ecol. 2001, 29, 1185.

2. Delprete, P.; Smith, L. B.; Klein, R. B.; Flora Ilustrada Catarinense, Herbário Barbosa Rodrigues: Santa Catarina, 2005.

3. Takeda, Y.; Zhang, H.; Masuda, T.; Honda, G.; Otsuka, H.; Sezik, E.; Yesilada, E.; Sun, H.; Phytochemistry 1997, 44, 1335.

4. Mahato, S. B.; Kundu, A. P.; Phytochemistry 1994, 37, 1517.

5. Banthorpe, D. V.; White, J. J.; Phytochemistry 1995, 38, 107.

6. Likhitwitayawuid, K.; Dej-Adisai, S.; Jonqbunprasert, V.; Krungkrai, J.; Planta Med. 1999, 65, 754.

7. Wu, T. S.; Huang, S. C.; Lai, J. S.; Teng, C. M.; Ko, F. N.; Kuoh, C. S.; Phytochemistry 1993, 32, 449.

8. Su, B. N.; Kang, Y. H.; Pinos, R. E.; Santarsiero, B. D.; Mesecar, A. D.; Soejarto, D. D.; Fong, H. H. S.; Pezzuto, J. M.; Kinghorn, A. D.; Phytochemistry 2003, 64, 293.

9. Aragão, P. C. A.; Toledo, J. B. T.; Morais, A. A.; Braz-Filho, R.; Quim. Nova 1990, 13, 254.

10. Shigemori, H.; Kagata, T.; Ishiyama, H.; Morah, F.; Ohsaki, A.; Kobayashi, J. I.; Chem. Pharm. Bull. 2003, 51, 58.

11. Naotaka, N.; Itoh, A.; Tanahashi, T.; Phytochemistry 1993, 32, 761.

12. Achenbach, H.; Lottes, M.; Waibel, R.; Karikas, G. A.; Correa, M. D.; Gupta, M. P.; Phytochemistry 1995, 38, 1537.

Submitted: May 5, 2011 Published online: August 25, 2011 


\section{Alkaloid and other Chemical Constituents from Psychotria stachyoides Benth.}

\section{Antonia T. A. Pimenta, ${ }^{a}$ Daniel E. A. Uchôa,${ }^{a}$ Raimundo Braz-Filho, ${ }^{b}$} Edilberto R. Silveira ${ }^{a}$ and Mary Anne S. Lima*,a

${ }^{a}$ Departamento de Química Orgânica e Inorgânica, Universidade Federal do Ceará, CP 12200, 60021-940 Fortaleza-CE, Brazil

${ }^{b}$ Centro de Ciências, Universidade Estadual do Norte Fluminense e

Universidade Federal Rural do Rio de Janeiro, 28013-600 Campos dos Goytacazes-RJ, Brasil

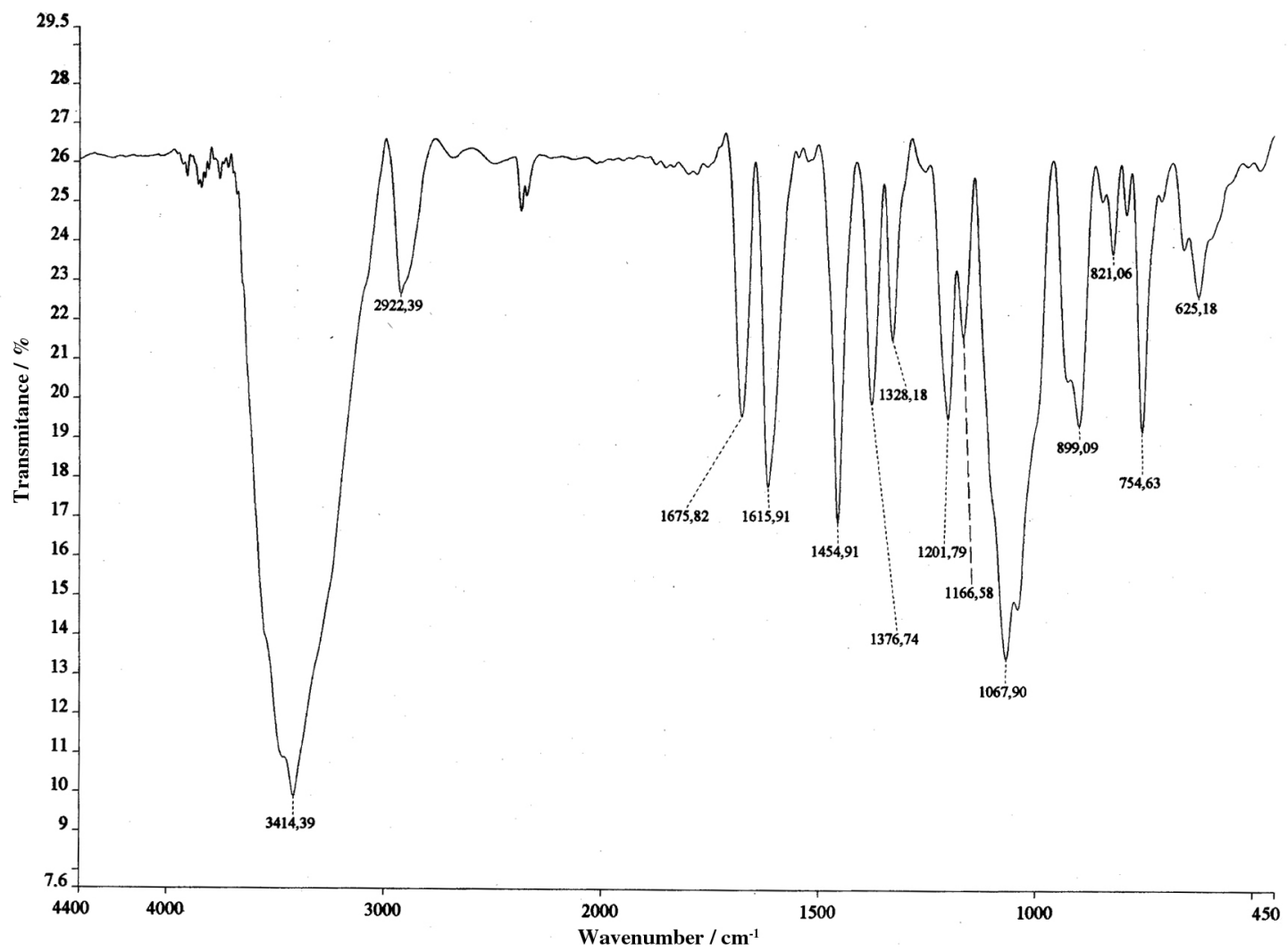

Figure S1. Infrared spectrum of $\mathbf{1}$ (KBr pellets). 


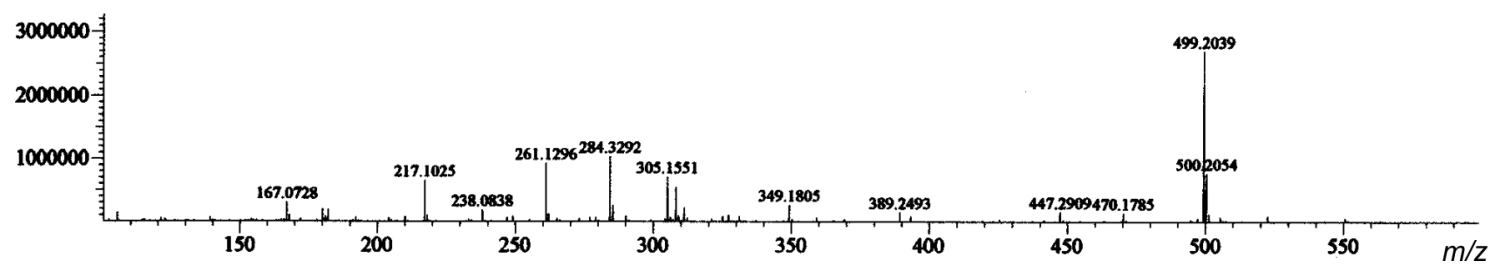

Figure S2. High resolution electrospray ionization mass spectrum of $\mathbf{1}$.

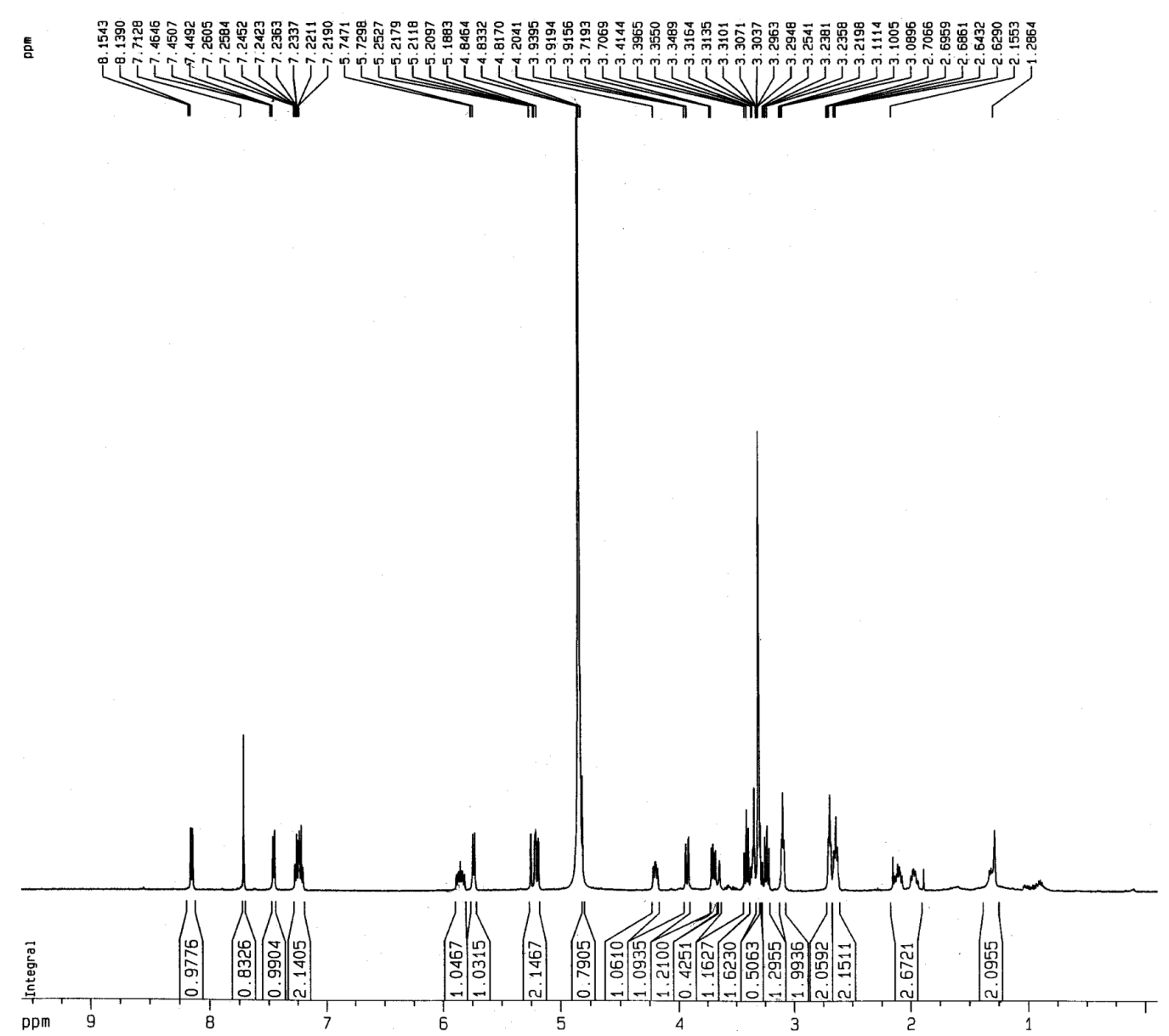

Figure S3. ${ }^{1} \mathrm{H}$ NMR spectrum of $\mathbf{1}(\mathrm{MeOD}, 500 \mathrm{MHz})$. 


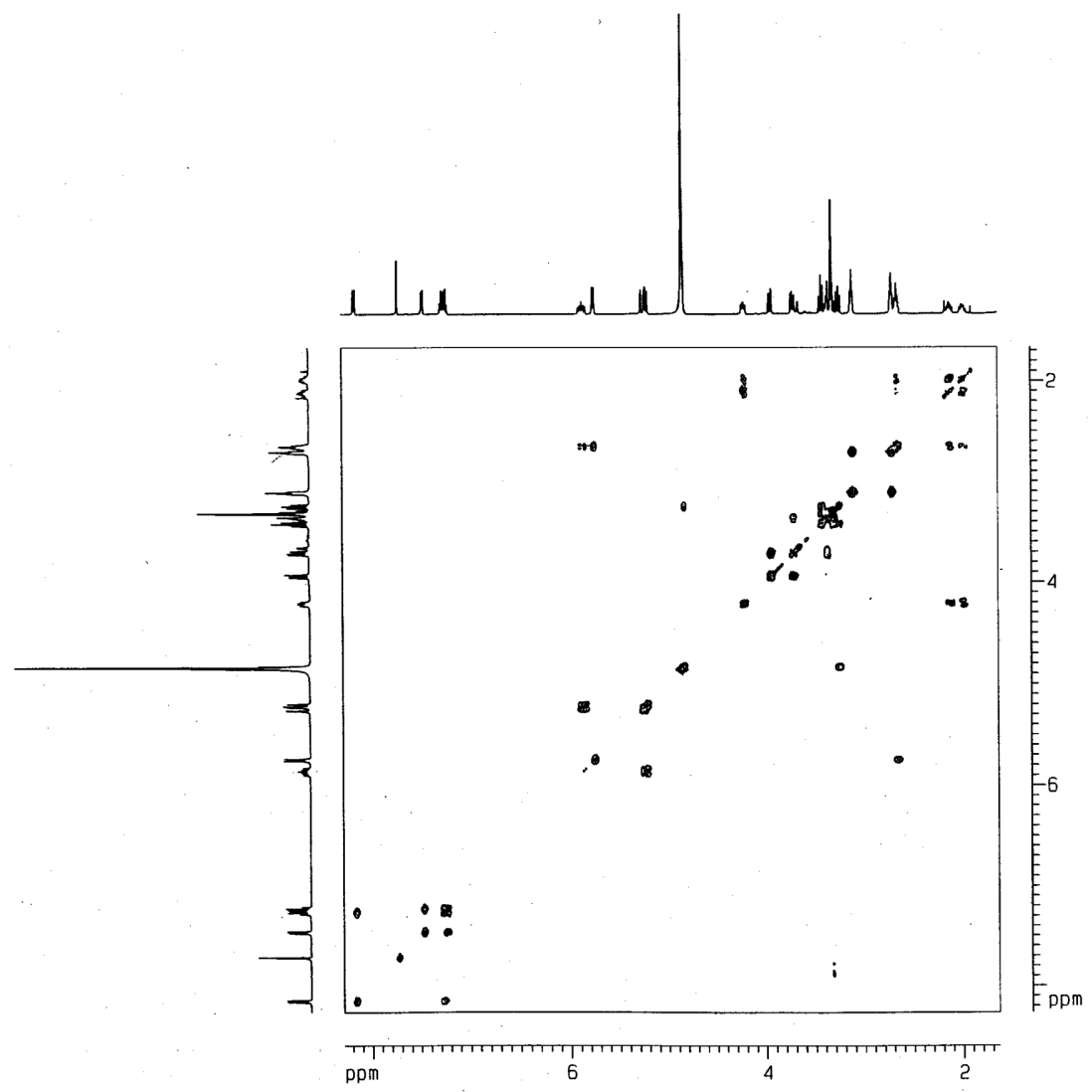

Figure S4. ${ }^{1} \mathrm{H},{ }^{1} \mathrm{H}$ COSY NMR spectrum of $\mathbf{1}\left(\mathrm{CD}_{3} \mathrm{OD}, 500 \times 500 \mathrm{MHz}\right)$.

镸

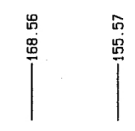

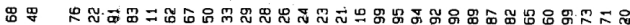

m.

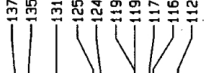

ill
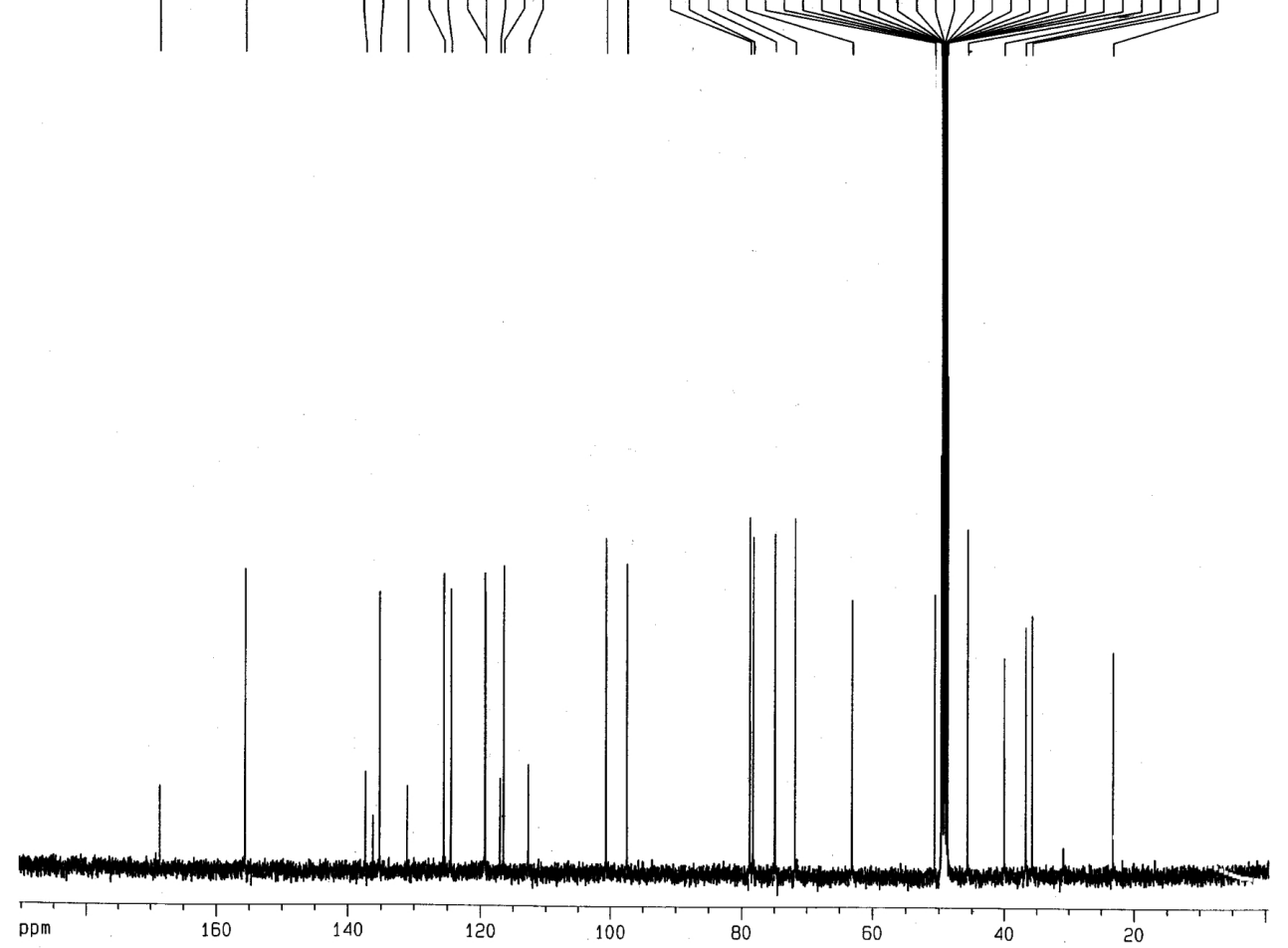

Figure S5. ${ }^{13} \mathrm{C}$ NMR spectrum of $\mathbf{1}\left(\mathrm{CD}_{3} \mathrm{OD}, 125 \mathrm{MHz}\right)$. 


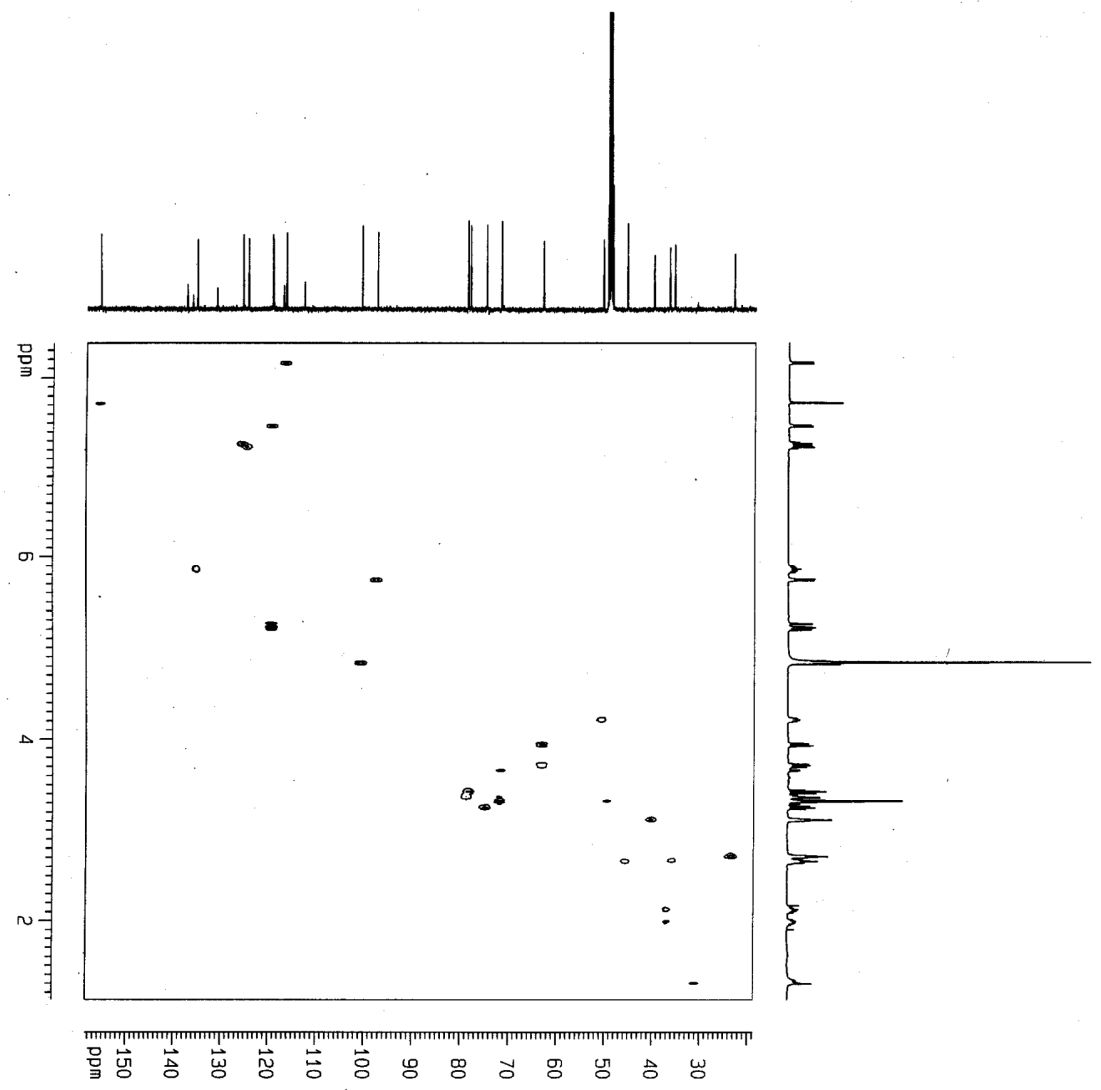

Figure S6. ${ }^{1} \mathrm{H},{ }^{13} \mathrm{C}$ HSQC-NMR spectrum of $\mathbf{1}\left(\mathrm{CD}_{3} \mathrm{OD}, 500 \times 125 \mathrm{MHz}\right)$.

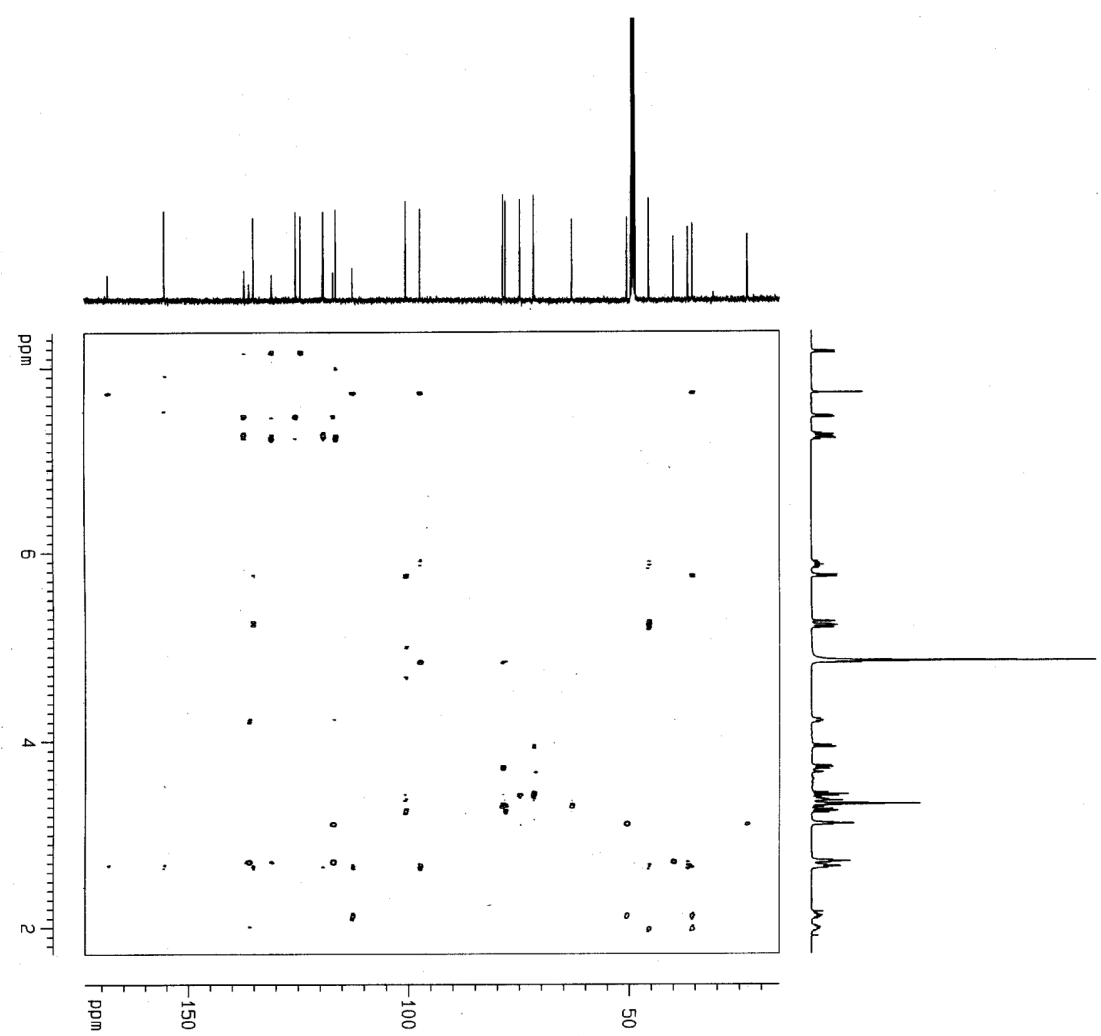

Figure S7. ${ }^{1} \mathrm{H},{ }^{13} \mathrm{C}$ HMBC-NMR spectrum of $\mathbf{1}\left(\mathrm{CD}_{3} \mathrm{OD}, 500 \times 125 \mathrm{MHz}\right)$. 


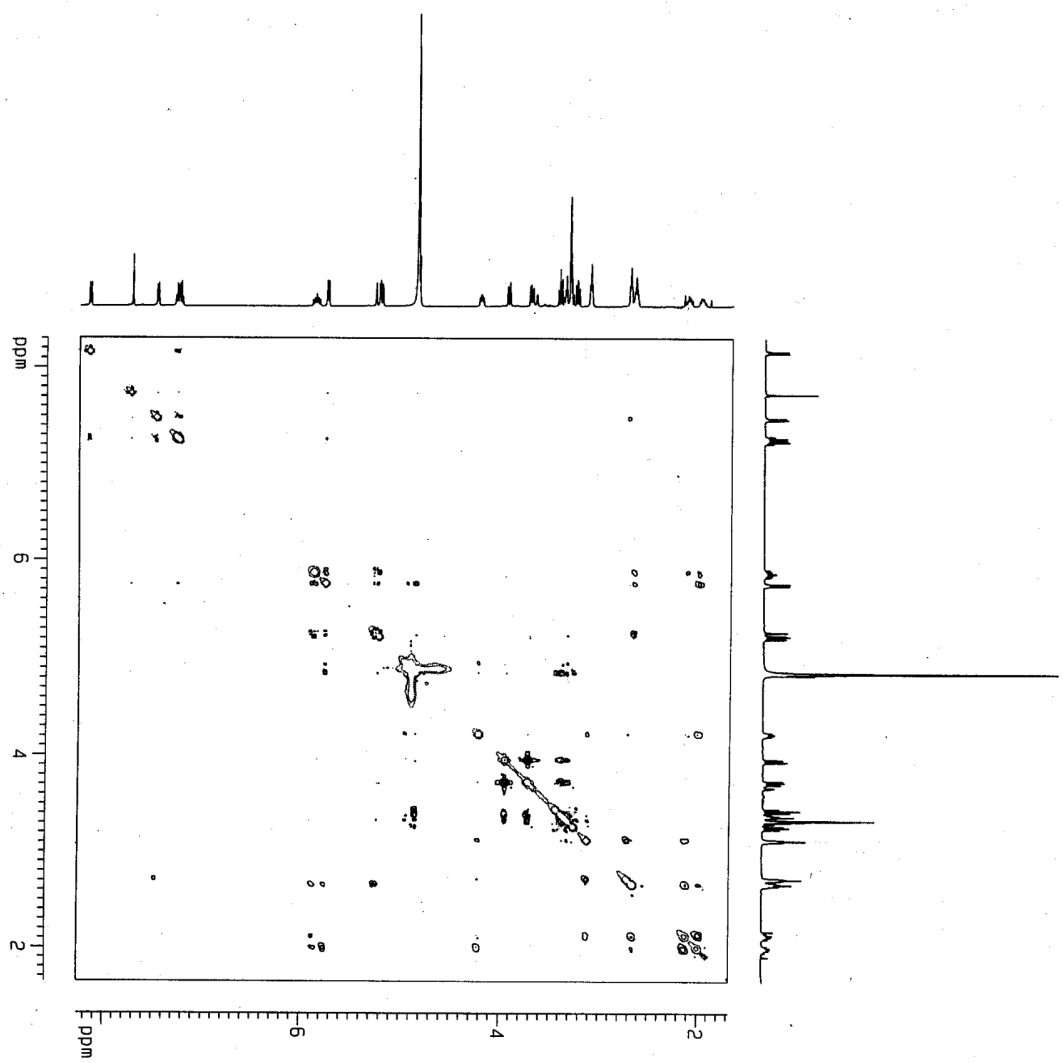

Figure S8. NOESY spectrum de $\mathbf{1}$. 